\title{
Sistem Rekomendasi Pemilihan Notebook Berbasis Website
}

\author{
Lu'lu'ul Mar' artus', Maryo Indra Majaruni ${ }^{2}$ \\ ${ }^{1}$ STT Cahaya Surya Kediri \\ ${ }^{2}$ STT Cahaya Surya Kediri \\ E-mail: ${ }_{1}^{1} 11 m$. artus@gmail.com, ${ }^{2}$ m.indra@cahayasurya.ac.id
}

\begin{abstract}
Abstrak
Laptop merupakan Perangkat Komputer yang memiliki fungsi sama persis dengan Komputer Desktop/ PC Desktop. Semakin majunya teknologi, laptop dikembangkan oleh masing-masing pemegang merk/brand dengan berbagai macam feature. Perubahan desain mengalami perkembangan yang sangat pesat, baik dari segi desain, kecepatan laptop, serta penambahan fitur-fitur yang lengkap. Pada saat ini, laptop juga dijual dengan harga relatif murah dan bisa menyesuaikan budget pengguna. Hal ini bisa dijadikan alternatif pengguna untuk memiliki perangkat elektronik laptop dengan harga yang relatif terjangkau. Sistem pendukung keputusan pemilihan laptop menggunakan metode TOPSIS ini dipilih karena mampu memilih alternatif terbaik dari sejumlah alternatif. Dalam hal ini alternatif yang dimaksud adalah laptop terbaik berdasarkan kriteria-kriteria yang ditentukan dengan langkah-langkah metode TOPSIS yang sederhana, mudah dipahami, efektif dan efisien. Proses implementasi metode TOPSIS ini dapat menghasilkan urutan alternatif dari nilai yang terbesar ke nilai yang terkecil, sehingga diharapkan laptop yang direkomendasikan benar - benar sesuai dengan keinginan, kebutuhan, dan kemampuan pengguna..
\end{abstract}

Kata Kunci-Topsis, Sistem Pendukung Keputusan, Pemilihan Laptop.

\section{PENDAHULUAN}

Laptop merupakan Perangkat Komputer yang memiliki fungsi sama persis dengan Komputer Desktop/ PC Desktop. Laptop atau Notebook memiliki design yang khusus dimana bisa dibawa kemana saja atau bersifat portable. Kekhususan pada laptop yaitu memiliki design yang relatif kecil dan ringan bila dibandingkan dengan Desktop Komputer.

Semakin majunya teknologi, laptop dikembangkan oleh masing-masing pemegang merk/brand dengan berbagai macam feature. Perubahan desain mengalami perkembangan yang sangat pesat, baik dari segi desain, kecepatan laptop, serta penambahan fitur-fitur yang lengkap. Pada saat ini, laptop juga dijual dengan harga relatif murah dan bisa menyesuaikan budget pengguna. Hal ini bisa dijadikan alternatif pengguna untuk memiliki perangkat elektronik laptop dengan harga yang relatif terjangkau.

Sistem pendukung keputusan pemilihan laptop menggunakan metode TOPSIS ini dipilih karena mampu memilih alternatif terbaik dari sejumlah alternatif. Alternatif yang dimaksud adalah laptop terbaik berdasarkan kriteria - kriteria yang ditentukan dengan langkah - langkah metode TOPSIS yang sederhana, mudah dipahami, efektif dan efisien. Proses implementasi metode TOPSIS ini dapat menghasilkan urutan alternatif dari nilai yang terbesar ke nilai yang terkecil, sehingga diharapkan laptop yang 
direkomendasikan benar - benar sesuai dengan keinginan, kebutuhan, dan kemampuan pengguna.

Penelitian sejenis yang berhubungan dengan penelitian ini dilakukan oleh Murnawan, Akhmad Fadjar Siddiq (2012).Ruang lingkup permasalahan hanya mencakup penilaian yang digunakan untuk mendukung pengambilan keputusan pemilihan telepon seluler menggunakan metode Technique for Order Preference by Similarity to Ideal Solution (TOPSIS), dan rating kecocokan setiap alternatif pada setiap kriteria dan tingkat kepentingan pada setiap kriteria dalam mendukung keputusan ditentukan melalui nilai angka (numeric). Tujuan dari penelitian ini yaitu diharapkan penerapan metode TOPSIS pada sistem pendukung keputusan pemilihan telepon seluler menjadi salah satu sistem pendukung keputusan yang dapat diandalkan untuk memudahkan proses pengambilan keputusan pemilihan telepon seluler berdasarkan kualitasnya [1]. Penelitian lain dilakukan oleh Pendik Pratama (2016). Penelitian ini menghasilkan sebuah aplikasi web yang memberikan informasi rekomendasi kepada user atau pengguna dalam hal ini merupakan calon wisatawan. Rekomendasi yang diberikan sistem didasarkan pada kriteria penilaian dan bobot kriteria setiap objek wisata kemudian diproses menggunakan metode Topsissehingga menghasilkan rekomendasi daftar tempat wisata [2].

\section{METODE PENELITIAN}

Metodologi penelitian Sistem Pendukung Keputusan Pemilihan Laptop Menggunakan Metode Topsis adalah

A. Pengumpulan Data

Sebelum membuat aplikasi yang diperlukan, dilakukan pengumpulan data terlebih dahulu. Pengumpulan data dapat dilakukan dengan beberapa cara, yaitu :

a. Data Internal

1. Interview yaitu dengan cara pengumpulan data dilakukan dengan cara tanya jawab secara langsung dengan pemilik Toko Raja Computer

2. Pengamatan langsung ke tempat penelitian dan tanya jawab dengan pengunjung mengenai pemilihan laptop yang saya teliti.

3. Studi Dokumen yaitu jenis pengumpulan data yang meneliti atau menganalisis data laptop.

b. Data Eksternal

Studi Literatur yaitu studi keputusan bertujuan untuk mendapatkan pengertian secara teori melalui sumber dari buku-buku.

B. Analisis Data

Proses analisisdata menggunakan Metode TOPSIS.Metode TOPSIS didasarkan pada konsep dimana alternatif terpilih yang terbaik tidak hanya memiliki jarak terpendek dari solusi ideal positif, namun juga memiliki jarak terpanjang dari solusi ideal negatif (Hwang, 1981) (Zeleny, 1982). Konsep ini banyak digunakan pada beberapa model MADM untuk menyelesaikan masalah keputusan secara praktis (Hwang, 1993), (Liang, 1999), (Yeh, 2000). Hal ini disebabkan : konsepnya yang sederhana dan mudah dipahami; komputasinya efisien; dan memiliki kemampuan untuk mengukur kinerja relatif dari alternatif-alternatif keputusan dalam bentuk matematis yang sederhana.

Secara umum, prosedur TOPSIS mengikuti langkah-langkah sebagai berikut :

- Membuat matriks keputusan yang ternormalisasi.

- Membuat matriks keputusan yang ternormalisasi terbobot.

- Menentukan matriks solusi ideal positif \& matriks solusi ideal negatif. 
- Menentukan jarak antara nilai setiap alternatif dengan matriks solusi ideal positif \& matriks solusi ideal negatif.

- Menentukan nilai preferensi untuk setiap alternatif.

TOPSIS membutuhkan rating kinerja setiap alternatif $A_{i}$ pada setiap kriteria $C_{j}$ yang ternormalisasi, yaitu

$r_{i j}=\frac{x_{i j}}{\sqrt{\sum_{i=1}^{m}}}(1)$.

Dengan $\mathrm{i}=1,2, \ldots, \mathrm{m} ;$ dan $\mathrm{j}=1,2, \ldots, \mathrm{n}$;

Solusi ideal positif $\mathrm{A}^{+}$dan solusi ideal negatif $\mathrm{A}^{-}$dapat ditentukan berdasarkan rating bobot ternormalisasi $\left(\mathrm{y}_{\mathrm{ij}}\right)$ sebagai :

$y_{i j}=w_{i} r_{i j}(2)$.

dengan $\mathrm{i}=1,2 \ldots, \mathrm{m}$ dan $\mathrm{j}=1,2, \ldots, \mathrm{n}$.

$A^{+}=\left(y_{1}^{+}, y_{2}^{+}, \ldots, y_{n}^{+}\right)$

$A^{-}=\left(y_{1}^{-}, y_{2}^{-}, \ldots, y_{n}^{-}\right)(3)$.

Dengan

$y_{j}^{+}=\left\{\begin{array}{c}\max _{i} y_{i j} \text { jika } j \text { adalah atribut keuntung } \\ \min _{i} y_{i j} \text { jika } j \text { adalah atribut biaya }\end{array}\right.$

$y_{j}^{-}=\left\{\begin{array}{c}\min _{i} y_{i j} \text { jika } j \text { adalah atribut keuntung } \\ \max _{i} y_{i j} \text { jika } j \text { adalah atribut biaya }\end{array}\right.$

$\mathrm{j}=1,2, \ldots, \mathrm{n}$.

Jarak antara alternatif $A_{i}$ dengan solusi ideal positif dirumuskan sebagai :

$D_{i}^{+}=\sqrt{\sum_{j=1}^{n}\left(y_{i}^{+}-y_{i}\right.}(5)$.

$\mathrm{i}=1,2, \ldots, \mathrm{m}$.

Jarak antara alternatif $A_{i}$ dengan solusi ideal negatif dirumuskan sebagai :

$D_{i}^{-}=\sqrt{\sum_{j=1}^{n}\left(y_{i j}-y_{i}^{-}\right.}(6)$.

$\mathrm{i}=1,2, \ldots, \mathrm{m}$.

Nilai preferensi untuk setiap alternatif $\left(\mathrm{V}_{\mathrm{i}}\right)$ diberikan sebagai :

$V_{i}=\frac{D_{i}^{i}}{D_{i}^{-}+}(7)$.

Nilai $V_{i}$ yang lebih besar mengindikasikan bahwa alternatif $A_{i}$ lebih dipilih. [3]

C. Perancangan Sistem

Setelah menganalisis dan mengetahui kebutuhan yang diperlukan, harus melewati tahap perancangan sistem terlebih dahulu, agar mempermudah proses pembuatan sistem ini, dan agar langkah - langkah sistem lebih terstruktur

1.Context Diagram

Context Diagram merupakan tingkatan tertinggi dalam diagram aliran data dan hanya memuat satu proses, menunjukkan sistem secara keseluruhan. Proses tersebut diberi nomor nol. Semua entitas eksternal yang ditunjukkan pada diagram konteks berikut aliran data-aliran data utama menuju dan dari sistem. Diagram tersebut tidak memuat penyimpanan data dan tampak sederhana untuk diciptakan, begitu entitas-entitas 
eksternal serta aliran data-aliran data menuju dan dari sistem diketahui menganalisis dari wawancara dengan user dan sebagai hasil analisis dokumen. [4]

Tabel 1. Simbol Context Diagram

\begin{tabular}{|l|l|}
\hline Simbol & Arti \\
\hline & \\
\hline
\end{tabular}

\section{Data Flow Diagram}

Diagram Alir Data (DAD) atau Data Flow Diagram (DFD) adalah suatu diagram yang menggunakan notasi-notasi untuk menggambarkan arus dari data sistem, yang penggunaannya sangat membantu untuk memahami sistem secara logika, tersruktur dan jelas. DFD merupakan alat bantu dalam menggambarkan atau menjelaskan DFD ini sering disebut juga dengan nama Bubble chart, Bubble diagram, model proses, diagram alur kerja, atau model fungsi. [4]

Tabel 2 Simbol DFD

\begin{tabular}{|c|c|}
\hline Simbol & Keterangan \\
\hline & $\begin{array}{l}\text { External Entity, merupakan kesatuan di } \\
\text { lingkungan luar sistem yang bisa berupa } \\
\text { orang, organisasi, atau sistem lain. }\end{array}$ \\
\hline & $\begin{array}{l}\text { Process, merupakan proses seperti perhitungan } \\
\text { aritmatik penulisan suatu formula atau } \\
\text { pembuatan laporan. }\end{array}$ \\
\hline & $\begin{array}{l}\text { Data Store (Simpan Data), dapat berupa suatu } \\
\text { file atau database pada sistem komputer atau } \\
\text { catatan manual. }\end{array}$ \\
\hline & $\begin{array}{l}\text { Data Flow (Arus Data), arus data ini mengalir } \\
\text { diantara proses, simpan data, dan kesatuan } \\
\text { luar. }\end{array}$ \\
\hline
\end{tabular}

D. Implementasi

Implementasi database, yaitu membuat database pada MySQL sesuai dengan rancangan database yang telah dibuat, serta implementasi antar muka pengguna, tampilan juga disesuaikan seperti rancangan yang dibuat. Setelah merancang tampilan, kemudian melakukan koding pada aplikasi. Kemudian dikoneksikan diantara database dengan tampilan antar mukan pengguna

E. Uji Coba 
Setelah implementasi selesai, uji coba sangat diperlukan untuk mengetahui proses proses yang masih perlu diperbaiki.

\section{HASIL DAN PEMBAHASAN}

3.1 Perancangan Sistem

Konteks Diagram untuk Sistem Pendukung Keputusan Pemilihan Laptop Menggunakan Metode Topsis dapat dilihat pada Gambar 1

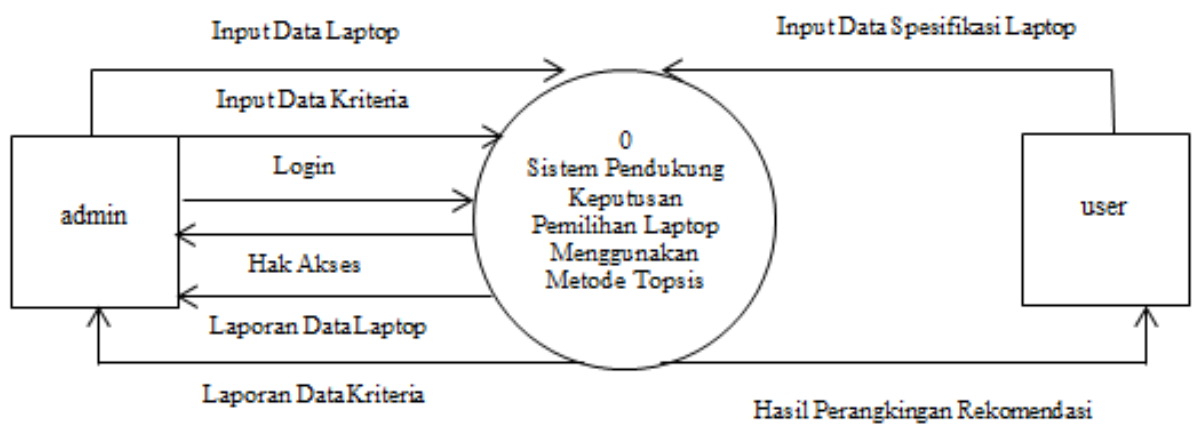

Gambar 1.Context Diagram

Pada conteks diagram diatas, pertama admin login ke sistem. Setelah login, admin memiliki hak akses dan dapat menginputkan data laptop, dan data kriteria ke sistem. Setelah itu, sistem memberikan laporan data laptop dan data kriteria ke admin. User menginputkan data spesifikasi laptop, setelah itu sistem memberikan hasil perangkingan rekomendasi pemilihan laptop menggunakan metode Topsis.

DFD Level 0 untuk Sistem Pendukung Keputusan Pemilihan Laptop Menggunakan Metode Topsis dapat dilihat pada Gambar 2

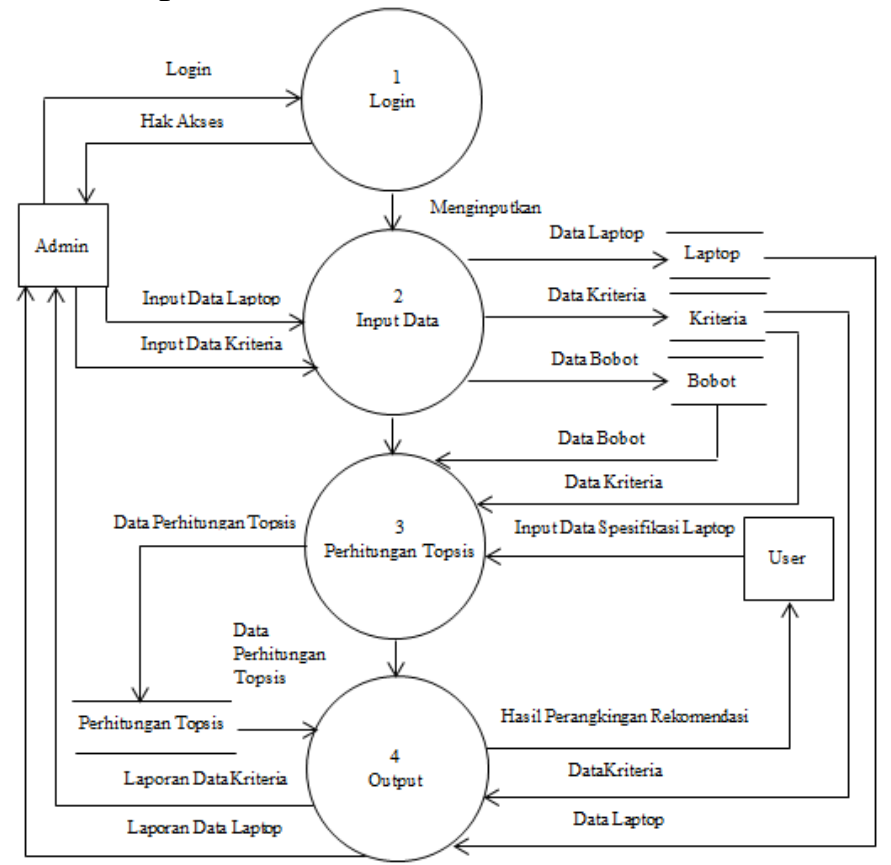

Gambar 2. DFD Level 0

Proses pertama adalah proses login. Admin login dan mendapatkan hak akses. Proses kedua adalah proses input data. Setelah mendapatkan hak akses admin menginputkan data laptop, kriteria, dan bobot. Proses ketiga adalah proses perhitungan topsis. Data kriteria dan bobot masuk ke proses perhitungan topsis dan user menginputkan data spesifikasi laptop yang diinginkan. Proses keempat adalah output. Setelah perhitungan 
topsis selesai user mendapatkan hasil perangkingan rekomendasi pemilihan laptop dan admin mendapat laporan data kriteria dan laptop.

DFD Level 1 Proses Perhitungan Topsisuntuk Sistem Pendukung Keputusan Pemilihan Laptop Menggunakan Metode Topsis dapat dilihat pada Gambar 3

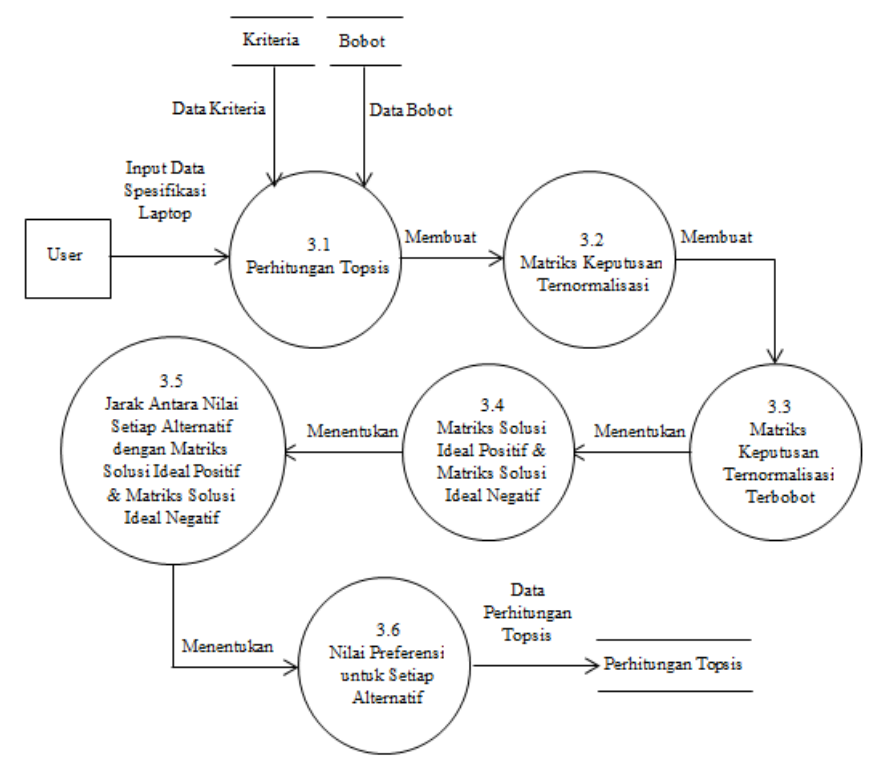

Gambar 3. DFD Level 1 Proses Perhitungan Topsis

Pada proses perhitungan topsis, user menginputkan data spesifikasi laptop yang diinginkan. Data kriteria dan bobot masuk ke proses Perhitungan Topsis. Setelah itu, membuat Matriks Keputusan Ternormalisasi, membuat Matriks Keputusan Ternormalisasi Terbobot, menentukan Matriks Solusi Ideal Positif \& Matriks Solusi Ideal Negatif, menentukan Jarak Antara Nilai Setiap Alternatif dengan Matriks Solusi Ideal Positif \& Matriks Solusi Ideal Negatif, dan proses terakhir yaitu menentukan Nilai Preferensi untuk Setiap Alternatif

3.2 Interface

A. InterfaceInput Data Laptop

Admin menginputkan data laptop yang terdiri dari Tipe Laptop, VGA, Processor, RAM, dan HDD. 


\section{Input Data Laptop}

Tipe Laptop
K43SV
VGA
Intel
Nvidia
OATI Radeon
Processor
O Dual Core
I3
I5
I7
RAM(GB)
2
HDD(GB)
500|
Submit

B. InterfaceInput Data Kriteria

Gambar 4. Input Data Laptop

Admin menginputkan ID Laptop, Merk Laptop, Ukuran Layar, VGA, Harga, dan Processor.

\section{Input Data Kriteria}

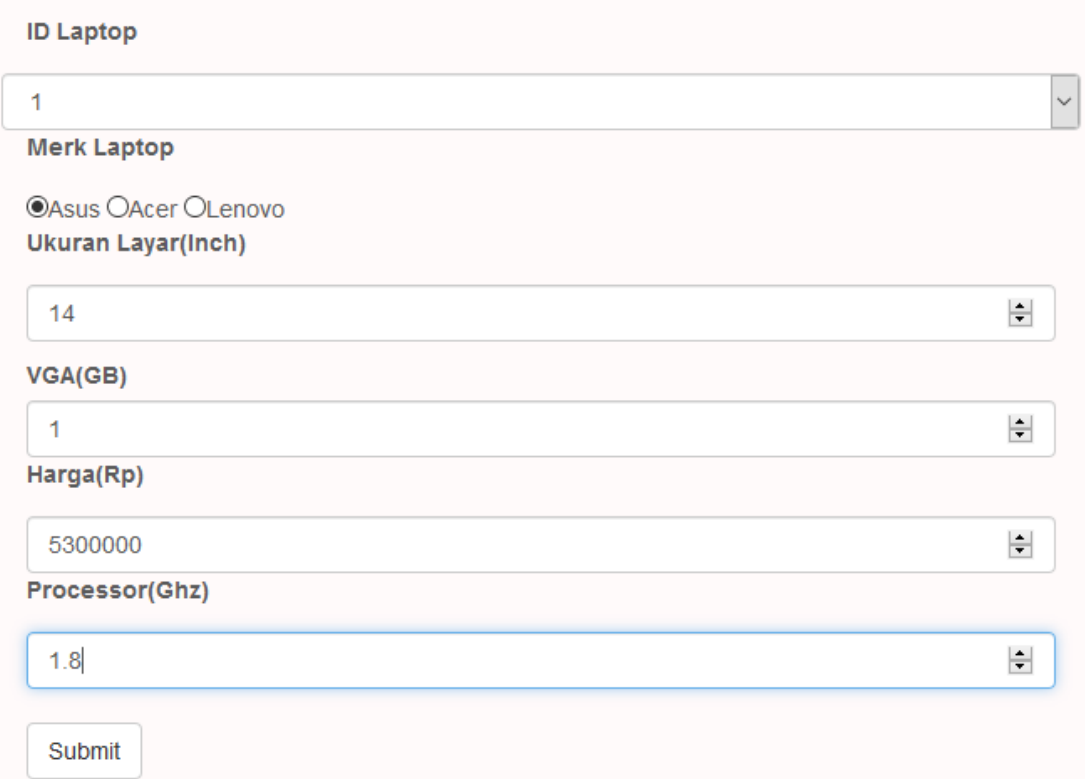

Gambar 5. Input Data Kriteria

C. InterfaceRekomendasi

User dapat memilih laptop yang akan dibandingkan untuk keperluan Gamming, Kantor, atau Pendidikan. Setelah itu, user mencentang kotak disebelah kiri data laptop yang akan dibandingkan dan tekan tombol Bandingkan. 
Pilih Beberapa Jenis Laptop yang ingin dibandingkan(Pendidikan)

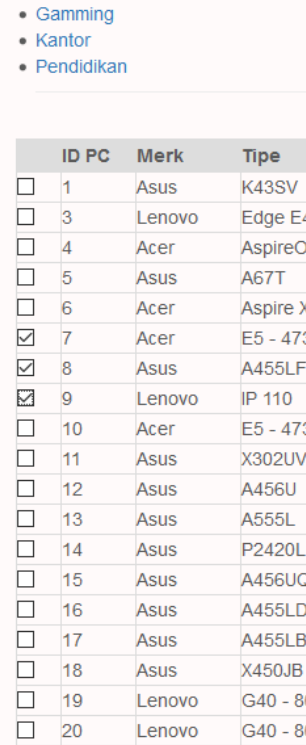

\begin{tabular}{|c|c|c|c|c|c|}
\hline Layar(Inch) & Processor & Harga & VGA & RAM(GB) & $\mathrm{HDD}(\mathrm{GB})$ \\
\hline 14 & i3 $-1.8 \mathrm{Ghz}$ & 5300000 & nvidia - 1GB & 2 & 500 \\
\hline 14 & $17-2.8 \mathrm{Ghz}$ & 7000000 & ati radeon - 2GB & 4 & 2000 \\
\hline 14 & $17-3.8 \mathrm{Ghz}$ & 7500000 & ati radeon - $2 \mathrm{~GB}$ & 4 & 2000 \\
\hline 14 & $17-3.6 \mathrm{Ghz}$ & 7700000 & nvidia - 2GB & 8 & 4000 \\
\hline 14 & $\mathrm{i} 3-1.6 \mathrm{Ghz}$ & 5500000 & intel - 1GB & 2 & 1000 \\
\hline 14 & i3 - 2Ghz & 5600000 & nvidia - 2GB & 4 & 500 \\
\hline 14 & i3 - 2Ghz & 5700000 & nvidia - 2GB & 4 & 500 \\
\hline 14 & $17-2.5 \mathrm{Ghz}$ & 7700000 & ati radeon - 2GB & 4 & 1000 \\
\hline 14 & i5 - $2.3 \mathrm{Ghz}$ & 7300000 & nvidia - 2GB & 4 & 1000 \\
\hline 13 & i5 - $2.3 \mathrm{Ghz}$ & 7550000 & nvidia - 2GB & 4 & 1000 \\
\hline 14 & i5 $-2.3 \mathrm{Ghz}$ & 8700000 & nvidia - 2GB & 4 & 1000 \\
\hline 15.5 & i3 $-1.7 \mathrm{Ghz}$ & 5350000 & nvidia - 2GB & 2 & 500 \\
\hline 14 & i5 - $2.2 \mathrm{Ghz}$ & 8950000 & nvidia - 2GB & 4 & 1000 \\
\hline 14 & $17-2.7 \mathrm{Ghz}$ & 9000000 & nvidia - 2GB & 4 & 1000 \\
\hline 14 & $17-3.1 \mathrm{Ghz}$ & 9450000 & nvidia - 2GB & 4 & 1000 \\
\hline 14 & i5 $-2.2 \mathrm{Gnz}$ & 7825000 & nvidia - 2GB & 4 & 1000 \\
\hline 14 & $17-2.6 \mathrm{Ghz}$ & 8700000 & nvidia - 2GB & 4 & 1000 \\
\hline 14 & i3 - 1.9Ghz & 5300000 & ati radeon - 2GB & 4 & 500 \\
\hline 14 & $15-2.7 \mathrm{Ghz}$ & 6800000 & ati radeon $-2 \mathrm{~GB}$ & 2 & 500 \\
\hline
\end{tabular}

Gambar 6. Rekomendasi - 1

\begin{tabular}{|c|c|c|c|c|c|c|c|c|c|}
\hline$\square$ & 33 & Asus & X441S & 14 & $\begin{array}{l}\text { Dual Core - } \\
1.6 \mathrm{Ghz}\end{array}$ & 3500000 & intel - 1GB & 2 & 500 \\
\hline$\square$ & 34 & Asus & TP201SA & 11.6 & $\begin{array}{l}\text { Dual Core - } \\
2.56 \mathrm{Ghz}\end{array}$ & 5000000 & intel - 1GB & 4 & 500 \\
\hline$\square$ & 35 & Lenovo & $310 \mathrm{~S}-111 \mathrm{AP}$ & 11.6 & $\begin{array}{l}\text { Dual Core - } \\
\text { 2.4Ghz }\end{array}$ & 2950000 & intel - $1 G B$ & 2 & 500 \\
\hline$\square$ & 36 & Lenovo & IP 110 & 14 & $\begin{array}{l}\text { Dual Core - } \\
1.6 \mathrm{Ghz}\end{array}$ & 3500000 & intel - 2GB & 4 & 500 \\
\hline$\square$ & 37 & Lenovo & IP 110 & 14 & $\begin{array}{l}\text { Dual Core - } \\
\text { 1.6Gnz }\end{array}$ & 3550000 & intel - 1 GB & 2 & 500 \\
\hline$\square$ & 38 & Acer & Z3- 451 & 14 & $\begin{array}{l}\text { Dual Core - } \\
3.5 \mathrm{Ghz}\end{array}$ & 6700000 & ati radeon - $2 \mathrm{~GB}$ & 4 & 500 \\
\hline$\square$ & 39 & Asus & X540YA & 15.6 & $\begin{array}{l}\text { Dual Core - } \\
1.5 \mathrm{Ghz}\end{array}$ & 3500000 & ati radeon - $2 \mathrm{~GB}$ & 2 & 500 \\
\hline$\square$ & 40 & Asus & X454Y & 14 & $\begin{array}{l}\text { Dual Core - } \\
2.2 \mathrm{Ghz}\end{array}$ & 4900000 & ati radeon - $2 \mathrm{~GB}$ & 4 & 500 \\
\hline$\square$ & 41 & Asus & X555DG & 15.6 & $\begin{array}{l}\text { Dual Core - } \\
3.2 \mathrm{Ghz}\end{array}$ & 6850000 & ati radeon - $2 \mathrm{~GB}$ & 4 & 1000 \\
\hline$\square$ & 42 & Asus & X550ZE & 15.6 & $\begin{array}{l}\text { Dual Core - } \\
\text { 3.6Ghz }\end{array}$ & 5600000 & ati radeon $-2 \mathrm{~GB}$ & 2 & 500 \\
\hline$\square$ & 43 & Asus & X555DQ & 15.6 & $\begin{array}{l}\text { Dual Core - } \\
\text { 3.3Ghz }\end{array}$ & 7200000 & ati radeon $-2 \mathrm{~GB}$ & 4 & 1000 \\
\hline$\square$ & 44 & Asus & X555QG & 15.6 & $\begin{array}{l}\text { Dual Core - } \\
\text { 3.4Ghz }\end{array}$ & 7400000 & ati radeon - $2 \mathrm{~GB}$ & 8 & 1000 \\
\hline$\square$ & 45 & Lenovo & IP 110 & 14 & $\begin{array}{l}\text { Dual Core - } \\
3.5 \mathrm{Ghz}\end{array}$ & 4300000 & ati radeon - $2 \mathrm{~GB}$ & 4 & 1000 \\
\hline$\square$ & 46 & Acer & v5 132 & 11.6 & $\begin{array}{l}\text { Dual Core - } \\
1 \mathrm{Ghz}\end{array}$ & 3000000 & intel - 1GB & 2 & 500 \\
\hline
\end{tabular}

Gambar 7. Rekomendasi - 2

D. Hasil Rekomendasi

Jika user telah menekan tombol Bandingkan, maka akan keluar hasil rekomendasi menggunakan metode Topsis.

\section{Tabel Nilai Preferensi (skor)}

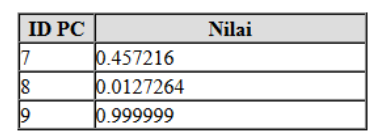

\section{Tabel Hasil Akhir}

\begin{tabular}{|c|c|c|c|c|c|c|c|c|c|}
\hline $\begin{array}{l}\text { ID } \\
\text { PC }\end{array}$ & Merk & Tipe & Layar(Inch) & Processor & Harga & VGA & RAM(GB) & HDD(GB) & \begin{tabular}{|c|} 
Skor \\
Perbandingan
\end{tabular} \\
\hline 9 & Lenovo & IP 110 & 14 & $7-2.5 \mathrm{Ghz}$ & 7700000 & ati radeon $-2 \mathrm{~GB}$ & 4 & 1000 & 0.999999 \\
\hline 7 & Acer & E5 - 473 & 14 & $\mathrm{i} 3-2 \mathrm{Ghz}$ & 5600000 & nvidia - 2GB & 4 & 500 & 0.457216 \\
\hline 8 & Asus & A455LF & 14 & i3-2Ghz & 5700000 & nvidia - 2GB & 4 & 500 & 0.0127264 \\
\hline
\end{tabular}

Gambar 8. Hasil Rekomendasi 


\section{KESIMPULAN}

Kesimpulan Berdasarkan pembahasan dan evaluasi dari bab terdahulu, maka dapat ditarik kesimpulan bahwa sistem memudahkan pemilihan laptop. Metode Topsis dapat diterapkan dalam Sistem Pendukung Keputusan Pemilihan Laptop sehingga memberikan kemudahan kepada pengguna kendala hal pemilihan laptop. Metode TOPSIS dapat digabungkan dengan metode lain, misalnya metode Analytical Hierarchy Process (AHP). Sistem sebaiknya dapat menangani lebih banyak kriteria misalkan RAM, HDD, dll

\section{DAFTAR PUSTAKA}

[1]. Murnawan, Siddiq, A.F., 2012, Sistem Pendukung Keputusan Menggunakan Metode Technique for Order by Similarity to Ideal Solution (TOPSIS), Jurnal Sistem Informasi (JSI), ISSN Print : 2085-1588 ISSN Online : 2355-4614, VOL. 4 No 1, April 2012

[2]. Pendik, P., 2016, Sistem Pendukung Keputusan dalam Pemilihan Lokasi Objek Wisata Menggunakan Metode Topsis, Artikel Skripsi, Fakultas Teknik Universitas Nusantara Persatuan Guru Republik Indonesia, Kediri

[3]. Kusumadewi, S., Hartati, S., Harjoko, A., \& Wardoyo, R., 2006, Fuzzy MultiAtribute Decision Making, First Edition, Graha Ilmu, Yogyakarta

[4]. Black, R., 17 April 2017, Pengertian dan Contoh dari Context Diagram, Data Flow Diagram, dan Flow Map, www.academia.edu/6078318/Pengertian_dan_Contoh_Dari_Context_Diagram_Dat a_Flow_Diagram_dan_Flow_Map_upload_by_rahmatdi.com 